\title{
Abnormal Dissolutions of Chlorpromazine Hydrochloride Tablets in Water by Paddle Method under a High Agitation Condition
}

\author{
Nobuo Aoyagi, ${ }^{*, a}$ Annie Policarpio Rimando, ${ }^{b}$ Kenichi Izutsu, ${ }^{a}$ Noriko Katori, ${ }^{a}$ and Shigeo KoJima ${ }^{a}$ \\ ${ }^{a}$ National Institute of Health Sciences; 1-18-1 Kamiyoga, Setagaya-ku, Tokyo 158-8501, Japan: and ${ }^{b}$ Bureau of Food and \\ Drugs; Alabang Muntinlupa City, Phillipines, 1770. Received January 28, 2003; accepted July 2, 2003
}

\begin{abstract}
All sugar-coated tablets of chlorpromazine hydrochloride except for those produced by one manufacture showed concave dissolution profiles in water by paddle method at $100 \mathrm{rpm}$ but not at $50 \mathrm{rpm}$. The study was undertaken to clarify the agitation-dependent abnormal dissolutions. The strange dissolutions were also observed in water at different ionic strengths but not in buffer solutions of $\mathrm{pH} 1.2,4.0$ and 6.8. When monitored, the pH's of water in dissolution vessels for the abnormal tablets increased with time at $100 \mathrm{rpm}$ and some of them exceeded pH 8 but did not at $50 \mathrm{rpm}$. The solubility of chlorpromazine hydrochloride decreased with the increase of $\mathrm{pH}$ which was too low to dissolve the whole amount of drug contained in a tablet at $\mathrm{pH} 8$. The elevation of $\mathrm{pH}$ seemed to be mainly brought about by dissolution of calcium carbonate popularly used for sugar-coated tablets, because larger amount of calcium ion was dissolved out from the abnormal tablets at $100 \mathrm{rpm}$ than from a normal tablet and from them at $50 \mathrm{rpm}$. These findings indicate that the concave dissolution profiles should be caused by the decrease of drug solubility with increase in $\mathrm{pH}$ of water, probably because of dissolution of calcium carbonate. We should pay attention to the change in $\mathrm{pH}$ of water which may differ depending on the agitation speed of dissolution tests.
\end{abstract}

Key words dissolution test; chlorpromazine hydrochloride tablet; change in $\mathrm{pH}$; precipitation; paddle method

In vitro dissolution tests for oral drugs are generally carried out at a low agitation speed in order to discriminate bioinequivalent products well. ${ }^{1)}$ However, tablets or capsules containing a large amount of low solubility drugs or insoluble excipients sometimes produce a mound at the bottom of the vessel after their disintegration by the paddle method, ${ }^{2)}$ resulting in the incomplete dissolution. For those products, the application of high agitation speeds seems to be preferable, which, however, may decrease the discriminating power of dissolution tests. In order to investigate the discrimination power, we carried out dissolution tests by JP paddle method at 50 and $100 \mathrm{rpm}$, using sugar-coated tablets of chlorpromazine hydrochloride as model products. During the study, we found agitation-dependent abnormal dissolution behaviors (concave dissolution profiles at $100 \mathrm{rpm}$ but normal at $50 \mathrm{rpm}$ ) for most tablets. We have never seen such strange dissolution behaviors and could not understand why they showed the concave profiles only at the high speed. The present study was undertaken to clarify the abnormal dissolution.

\section{Experimental}

Formulation Sugar-coated tablets of four different manufactures (A, B, $\mathrm{C}$ and D) containing $12.5-100 \mathrm{mg}$ of chlorpromazine hydrochloride were used. The $25 \mathrm{mg}$ tablet of manufacture A is shown as A-25.

Dissolution Test Dissolution tests were carried out at $37{ }^{\circ} \mathrm{C}$ by JP paddle method, using $900 \mathrm{ml}$ of water, the 1st fluid of $\mathrm{JP}(\mathrm{pH} 1.2), 0.05 \mathrm{M}$ sodium acetate buffer ( $\mathrm{pH} 4.0$ ), $\mathrm{pH} 6.8$ solution (JP pH 6.8 sodium phosphate buffer: water $=1: 1)$ and JP $\mathrm{pH} 7.0-8.0$ phosphate buffer solutions. The amount of drug dissolved was spectrophotometrically measured.

Solubility Fifty milligrams of chlorpromazine hydrochloride powder was added to $20 \mathrm{ml}$ of $\mathrm{pH} 7.0,7.6,8.0$ and 8.2 phosphate buffer solutions prepared referring to JP phosphate buffer solutions. The amount of drug dissolved was spectrophotometrically measured after shaking the test tubes containing each buffer solution at $37^{\circ} \mathrm{C}$ for $24 \mathrm{~h}$.

Effect of Excipient on Medium pH and Dissolved Amount of Drug Dissolution tests for chlorpromazine hydrochloride tablets were performed in $900 \mathrm{ml}$ of water for $3 \mathrm{~h}$ at 50 or $100 \mathrm{rpm}$. Then, the supernatant fluid was discarded and $900 \mathrm{ml}$ of aqueous solution containing $50 \mathrm{mg}$ of chlorpromazine hydrochloride was added to the residue which was agitated at
$100 \mathrm{rpm}$. The changes in the medium $\mathrm{pH}$ and amount of drug dissolved in the fluid were monitored. In the experiment investigating effects of calcium carbonate, $20 \mathrm{mg}$ calcium carbonate (JP) was added to aqueous solution of chlorpromazine hydrochloride $(50 \mathrm{mg}$ in $900 \mathrm{ml}$ ) agitated at $100 \mathrm{rpm}$.

Determination of Calcium Ion Dissolved from Tablet Dissolution tests for chlorpromazine hydrochloride tablets were performed in $900 \mathrm{ml}$ of water at 50 and $100 \mathrm{rpm}$ and the concentration of calcium ion was measured by ion chromatography with a conductivity detector (Shimadzu CDD10Avp) under the following condition: cation column, Shim-pack IC-C3 $\left(100 \times 4.6 \mathrm{~mm}\right.$ I.D., Shimadzu Co., Kyoto); column temperature, $40^{\circ} \mathrm{C}$; mobile phase, $2.5 \mathrm{~mm}$ oxalic acid; flow rate, $1.2 \mathrm{ml} / \mathrm{min}$.

\section{Results and Discussion}

Dissolution of Chlorpromazine Hydrochloride Tablet Dissolution tests were first carried out, using A-50 in water by JP paddle method at 50 and $100 \mathrm{rpm}$. It exhibited normal dissolution at $50 \mathrm{rpm}$ but concave dissolution profiles at $100 \mathrm{rpm}$ (Fig. 1). Dissolutions of other tablets were also measured which revealed that all products except for those of manufacture D similarly gave uncommon dissolutions at

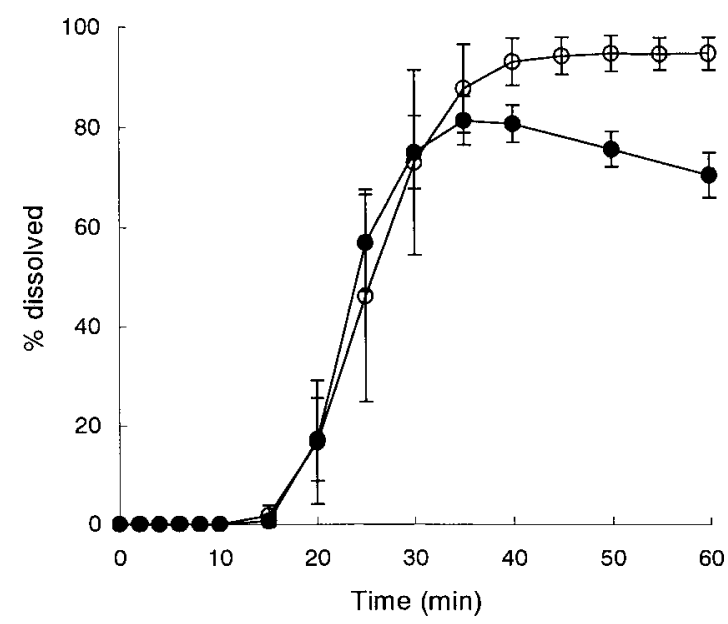

Fig. 1. Dissolution Profiles (Mean \pm S.D., $n=6$ ) of A-50 by JP Paddle Method at $50(\bigcirc)$ and $100 \mathrm{rpm}(\bullet)$ 


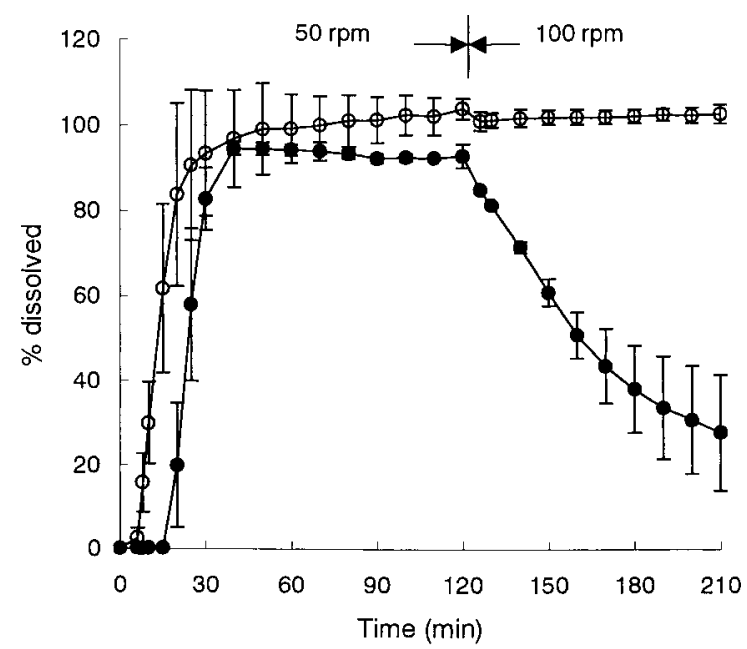

Fig. 2. Dissolution Profiles (Mean \pm S.D., $n=3$ ) of A-50 (O) and D-50 (O) by JP Paddle Method at $50 \mathrm{rpm}$ by $120 \mathrm{~min}$ and Thereafter at $100 \mathrm{rpm}$

$100 \mathrm{rpm}$ (data not shown), although all tablets showed ordinal dissolutions at $50 \mathrm{rpm}$. When dissolution tests for A-50 and D-50 giving abnormal and normal dissolutions, respectively, were carried out at $50 \mathrm{rpm}$ for the first $120 \mathrm{~min}$ and then at $100 \mathrm{rpm}, \mathrm{A}-50$ showed a significant decrease in the dissolved amount just after the increase in the rotation speed but D-50 did not (Fig. 2). There has been no report on such a strange dissolution by now, which specifically occurred only at a high agitation speed. However, A-50 showed a normal dissolution in $\mathrm{pH} 1.2, \mathrm{pH} 4.0$ and 6.8 buffer solutions even at $100 \mathrm{rpm}$ (data not shown). These findings indicated that the abnormal dissolution behaviors at the high speed should be related with the low ionic strength or variable $\mathrm{pH}$ of water. To clarify it, the dissolution of drug from A-50 was measured in water containing 0.01 and $0.1 \mathrm{~mol} / 1$ sodium chloride at $100 \mathrm{rpm}$ but it still showed the concave dissolution profiles regardless of the ionic strength.

Change in pH of Water during Dissolution Test The remaining possible factor affecting the dissolution is variable $\mathrm{pH}$ of water. Thus, we measured the $\mathrm{pH}$ of water in each vessel during dissolution tests which revealed that $\mathrm{pH}$ 's of water were below $\mathrm{pH} 7$ at $50 \mathrm{rpm}$ for all tablets but those at $100 \mathrm{rpm}$ for abnormal tablets increased with time as shown in Fig. 3, in which the pH's for A-12.5 and A-25 showing profound concave dissolution profiles provided very high pHs $(>\mathrm{pH}$ 8.5). When the solubility of chlorpromazine hydrochloride $\left.\left(\mathrm{p} K_{\mathrm{a}}=9.2\right)^{3}\right)$ was measured, the solubility significantly decreased with the increase of $\mathrm{pH}$ (solubility: $>2.5$, $0.104,0.075,0.008 \mathrm{mg} / \mathrm{ml}$ at $\mathrm{pH} 7.0,7.6,8.0,8.2$, respectively). It suggested that the concave dissolution profile at $100 \mathrm{rpm}$ should be brought about by the precipitation of the drug due to the decrease of drug solubility with the increase of medium $\mathrm{pH}$. The precipitation at a high $\mathrm{pH}$ was observed when $100 \mathrm{ml}$ of aqueous solution containing $25 \mathrm{mg}$ chlorpromazine hydrochloride was added to $800 \mathrm{ml}$ of 8.0 buffer at $37^{\circ} \mathrm{C}$ and stirred at $100 \mathrm{rpm}$ where white fine particles were attached to the metal blade.

Effect of Excipient on Medium pH and Dissolved Amount of Drug The increase in $\mathrm{pH}$ of water should be caused by the dissolution of alkaline excipients contained in abnormal tablets. However, it was not understandable why
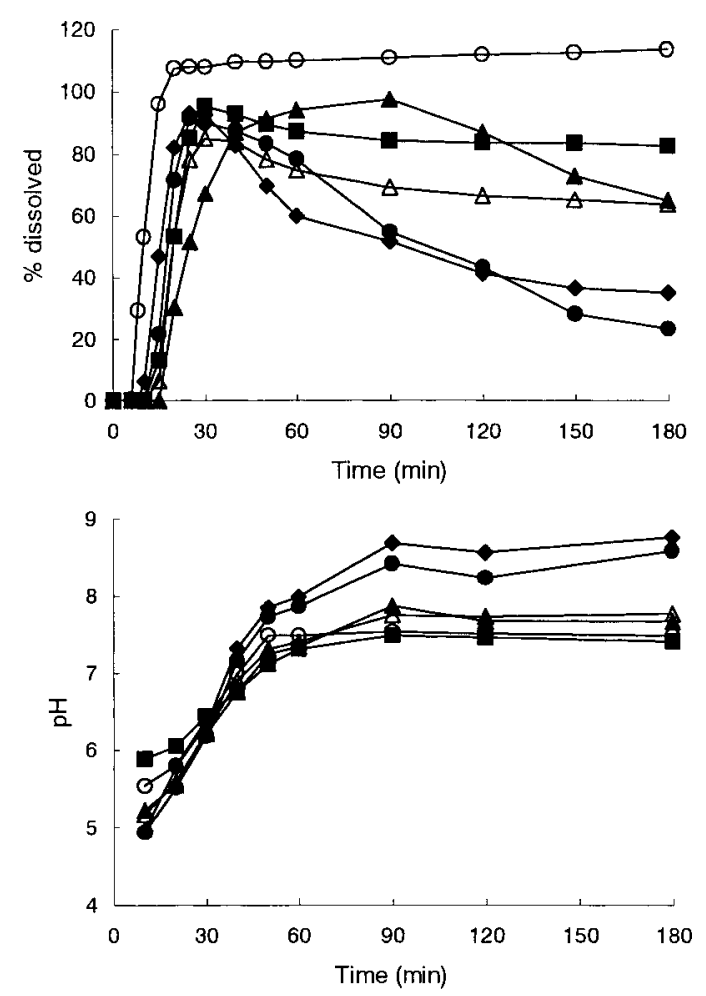

Fig. 3. Dissolution Profiles and Changes in $\mathrm{pH}$ of Water for A-12.5 $(\diamond)$,

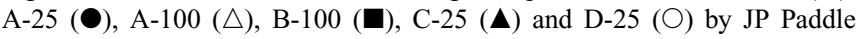
Method at $100 \mathrm{rpm}$

they dissolved only at $100 \mathrm{rpm}$. When carefully observed, all tablets disintegrated into fine particles at $100 \mathrm{rpm}$ which were dispersed well in the test fluid, although all tablets formed mounds at the bottom of vessel after the disintegration at $50 \mathrm{rpm}$. The observation indicated that some alkaline excipients which remained in the mound at $50 \mathrm{rpm}$ should be dissolved under the high agitation condition and increase the $\mathrm{pH}$ of water. To clarify it, we carried out dissolution tests using A-50 and D-50 showing abnormal and normal dissolutions at $50 \mathrm{rpm}$ or $100 \mathrm{rpm}$ for $3 \mathrm{~h}$ and the supernatants were discarded. To the residues, $900 \mathrm{ml}$ of aqueous solution containing $50 \mathrm{mg}$ chlorpromazine hydrochloride was added and stirred at $100 \mathrm{rpm}$. The medium $\mathrm{pH}$ and the dissolved amount of drug were monitored. As shown in Fig. 4, the medium $\mathrm{pH}$ more increased with the decrease in dissolved amount of drug in the presence of residual excipients obtained from A50 at $50 \mathrm{rpm}$ than in the presence of those of D-50, indicating that A-50 should contain larger amount of alkaline excipients. On the other hand, there were no significant changes in medium $\mathrm{pH}$ and dissolved amount in the presence of residual excipients of A-50 as well as D-50 which were obtained from dissolution tests at $100 \mathrm{rpm}$. The findings suggest that the alkaline excipients should be almost dissolved under the vigorous agitation condition at $100 \mathrm{rpm}$ and should not remain in the residue.

Calcium Ion Dissolved from Tablet As the alkaline excipient, calcium carbonate was deduced, since it is popularly used for sugar-coated tablets ${ }^{4)}$ and, because of the low solubility and heavy specific gravity, the excipient will not disperse and hence dissolve well in the test fluid at $50 \mathrm{rpm}$, a low speed. Accordingly, we measured calcium ion dissolved from tablets in water during dissolution tests. The experiment 

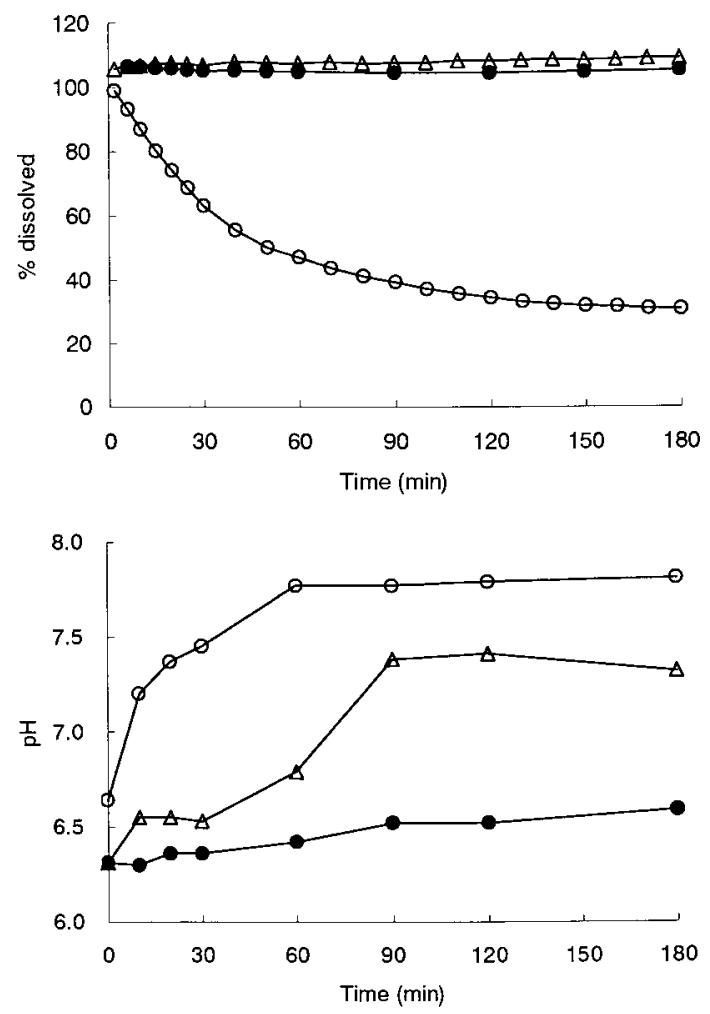

Fig. 4. Changes in Dissolved Amount of Drug (Upper Figure) and $\mathrm{pH}$ of Water (Lower Figure) at $100 \mathrm{rpm}$ in the Presence of Residual Excipients of Tablets Obtained from A-50 $(\bigcirc)$ and D-50 $(\triangle)$ by Dissolution Tests in Water at $50 \mathrm{rpm}$ for $3 \mathrm{~h}$ and from $\mathrm{A}-50(\bullet)$ at $100 \mathrm{rpm}$

revealed that calcium ion dissolved more from A-50, B-100 and $\mathrm{C}-25$ at $100 \mathrm{rpm}$ than from D-50 showing normal dissolution (Fig. 5). Calcium ion did not dissolve much from any tablets at $50 \mathrm{rpm}$. The calcium concentration (approximately $8 \mathrm{mg} / \mathrm{l}$ ) at $3 \mathrm{~h}$ for A-50 almost corresponds to $20 \mathrm{mg}$ calcium carbonate dissolved. When $20 \mathrm{mg}$ calcium carbonate was added to aqueous solution of chlorpromazine hydrochloride $(50 \mathrm{mg} / 900 \mathrm{ml})$ stirred at $100 \mathrm{rpm}$, the dissolved amount of drug significantly decreased with time as shown in Fig. 6, where the fluid $\mathrm{pH}$ was near to $\mathrm{pH} 8$. The profile of dissolved amount and fluid $\mathrm{pH}$ were similar to those observed for the residual excipients of A-50 in Fig. 4. The findings indicate that the increase in $\mathrm{pH}$ of water for abnormal tablets at $100 \mathrm{rpm}$ should be mainly caused by the dissolution of calcium carbonate employed for sugar-coated tablets, although other excipients might affect the $\mathrm{pH}$ of water as well. The content of calcium carbonate in tablets of manufacture D might be smaller than others or the dissolution of calcium carbonate might be limited due to the incomplete disintegration into fine particles.

Our previous study on indomethacin preparations showed that water is advantageous for discriminating poorly available products compared with other $\mathrm{pH}$ solutions. ${ }^{5}$ However, there have been very limited studies on the relation between dissolution tests in water and bioavailability until now. Therefore, it is difficult to predict whether the tablets showing abnormal dissolution in water will also show strange in vivo absorptions or not. Water is empirically known as a discriminative medium $^{6}$ and used as a test fluid together with other physiological $\mathrm{pH}$ buffers for in vitro equivalence tests for minor changes in formulation of oral dosage forms in $\mathrm{Japan}^{7)}$ as
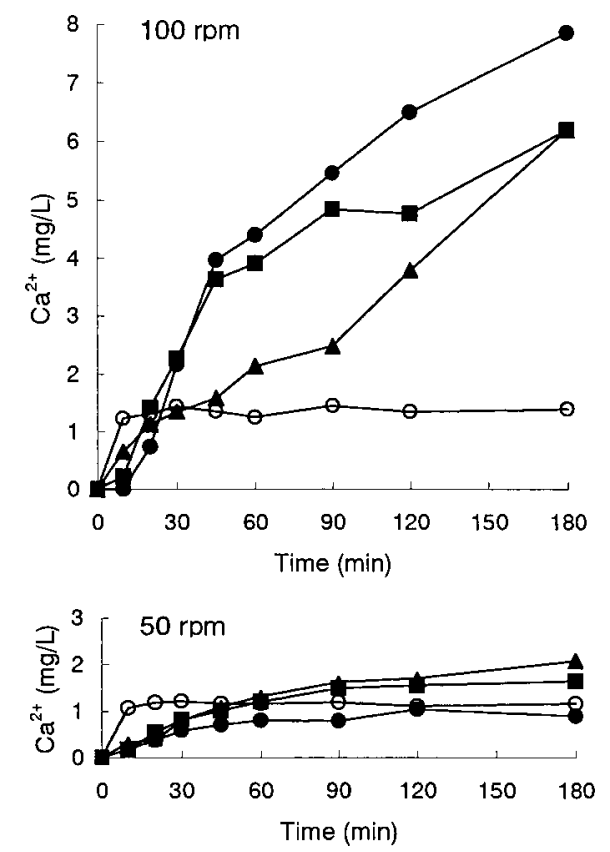

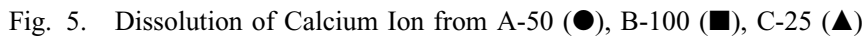
and D-50 (O) in Water by Paddle Method at $100 \mathrm{rpm}$ and at $50 \mathrm{rpm}$

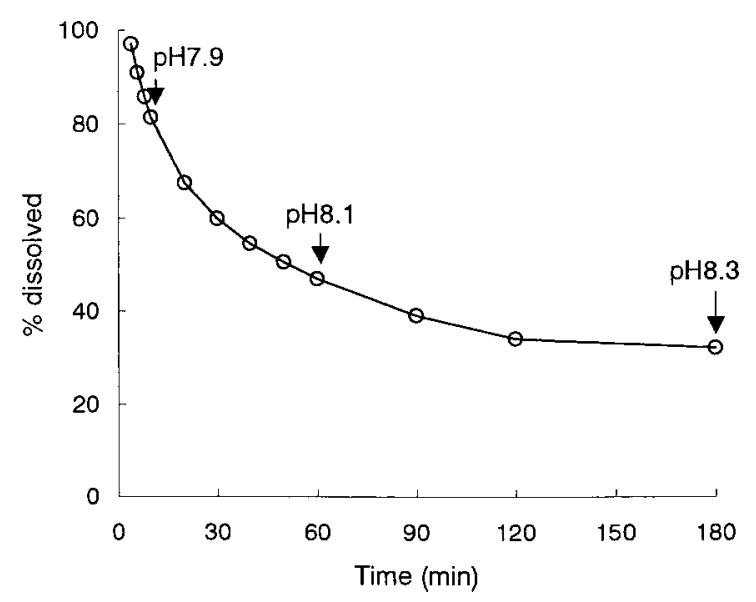

Fig. 6. Changes in Dissolved Amount of Drug $(50 \mathrm{mg} / 900 \mathrm{ml})$ and $\mathrm{pH}$ of Water at $100 \mathrm{rpm}$ in the Presence of $20 \mathrm{mg}$ Calcium Carbonate

well as in U.S.A., $\left.{ }^{8}\right)$ where water is employed for low solubility drugs. However, the use of water has been criticized because of the non-physiological medium, variable $\mathrm{pH}$ and surface tension. ${ }^{9,10)}$ Here, we have to consider the main purpose of the in vitro equivalence test employed as a surrogate for human study, which will be to assess the potential risk of bioinequivalence. For the purpose, it is desirable to carry out dissolution tests not only in physiological $\mathrm{pH}$ fluids but also in water, a discriminative medium, to assure bioequivalence by in vitro tests without human studies. This approach is recommendable to avoid the risk of bioinequivalence if it is not much difficult to prepare test products showing similar dissolution even in water with the reference product. However, water should be removed from the test fluids when it is clarified that water is not suitable for the in vitro equivalence due to poor in vitro-in vivo relations.

The present study gave a conclusion that the agitation-dependent abnormal dissolutions in water should be caused by 
the precipitation of the drug because of the decease of drug solubility with the increase in $\mathrm{pH}$ of water. The change in $\mathrm{pH}$ was probably ascribed to the dissolution of calcium carbonate, an alkaline excipient, widely used for sugar-coated tablets. The findings tell us that we have to pay attention to the change in $\mathrm{pH}$ of water which may differ depending on the agitation speed of dissolution testing.

\section{References and Notes}

1) Shah V. P, Gurbarg M., Noory A., Dighe S., Skelly J. P., J. Pharm. Sci., 81, 500-503 (1992).

2) Qureshi S. A., Shabnam J., Eur. J. Pharmaceut. Sci., 12, 271-276 (2001).

3) Chatten J. G., Harris L. E., Anal. Chem., 34, 1459-1501 (1962).

4) Takagishi Y., Nagata S., "Iyakuhin no Kaihatsu: Seizai Sozai 1," ed. by
Ichibagase H., Uekama K., Otagiri M., Hirokawa Publishing, Tokyo, 1990, pp. 198-214.

5) Aoyagi N., Morihara M., Ishi F., Ogata H., Abstract 3 of the 120th Meeting of the Pharmaceutical Society of Japan, 2000, p. 124.

6) Leeson L. J., Dissolution Technologies, 7, 16-19 (2000).

7) Guideline for Bioequivalence Studies for Formulation Changes of Oral Solid Dosage Forms $\langle$ http://www.nihs.go.jp/drug/DrugDiv-E.html〉

8) SUPAC-IR: Immediate-Release Solid Oral Dosage Forms: Scale-Up and Post-Approval Changes: Chemistry, Manufacturing and Controls, In Vitro Dissolution Testing, and In Vivo Bioequivalence Documentation: 〈http://www.fda.gov/cder/guidance/〉.

9) Noory C., Tran N., Ouderkirk L., Brown S., Perry J., Lopez J., Colon M., Faberlle M., Henry K., Rorberg J., Ali S. N., Shah V., Dissolution Technologies, 6, 6-7 (1999).

10) FIP guideline for dissolution testing of solid oral products (final draft, 1995), Drug Information J., 30, 1071-1084 (1996). 